\title{
Amazon drought raises research doubts
}

A once-in-a-century drought struck much of the Amazon rainforest in 2005, reducing rainfall by $60-75 \%$ in some areas - and giving scientists a window on to a future coloured by climate change.

The drought foreshadowed the Amazon drying that many climate modellers expect to see in a warmer world. But five years on, a spate of research, including 13 papers published on 20 July in a special issue of the journal New Phytologist, shows that researchers are still grappling with the impact of drought and what it could reveal about the fate of the world's largest tropical forest, a major carbon storehouse.

The debate began with a 2007 study ${ }^{1}$ that used data gathered by NASA's Terra satellite to argue that the canopy of the Amazon rainforest grew and "greened up" during the drought - suggesting that the rainforest could be resilient to dryness, at least for short periods. The phenomenon can be attributed to fewer clouds and more sunlight. But in March, a study using the same satellite data added confusion to the issue when it failed to find excessive greening ${ }^{2}$.

These uncertainties are exposing the limits of space-based sensors that were designed 20 years ago, says Gregory Asner, an expert in remote sensing at the Carnegie Institution's global ecology programme at Stanford University in California. "It's nobody's fault - these guys are trying to squeeze blood from a stone," says Asner, co-author of a review of Amazon drought research in the New Phytologist issue ${ }^{3}$. "These issues are not going to be resolved by technology that is in orbit today."

The debate over the greening fuelled accusations that the Intergovernmental Panel on Climate Change had exaggerated when it suggested in its 2007 report that $40 \%$ of the Amazon region is highly vulnerable to drought. But longer-term studies on the ground, although limited in range, have consistently showed that the forest is sensitive to drying. A 2009 analysis of ground plots ${ }^{4}$ found decreased growth and increased tree death from the 2005 drought, and one of the New Phytologist papers documents similar results from the longest-running Amazon drought experiment ${ }^{5}$. After siphoning off half of the rain that fell across a 1-hectare plot, researchers observed a $30 \%$ reduction in tree growth and a doubling in tree death over the course of 7 years.

But there might have been more to 2005

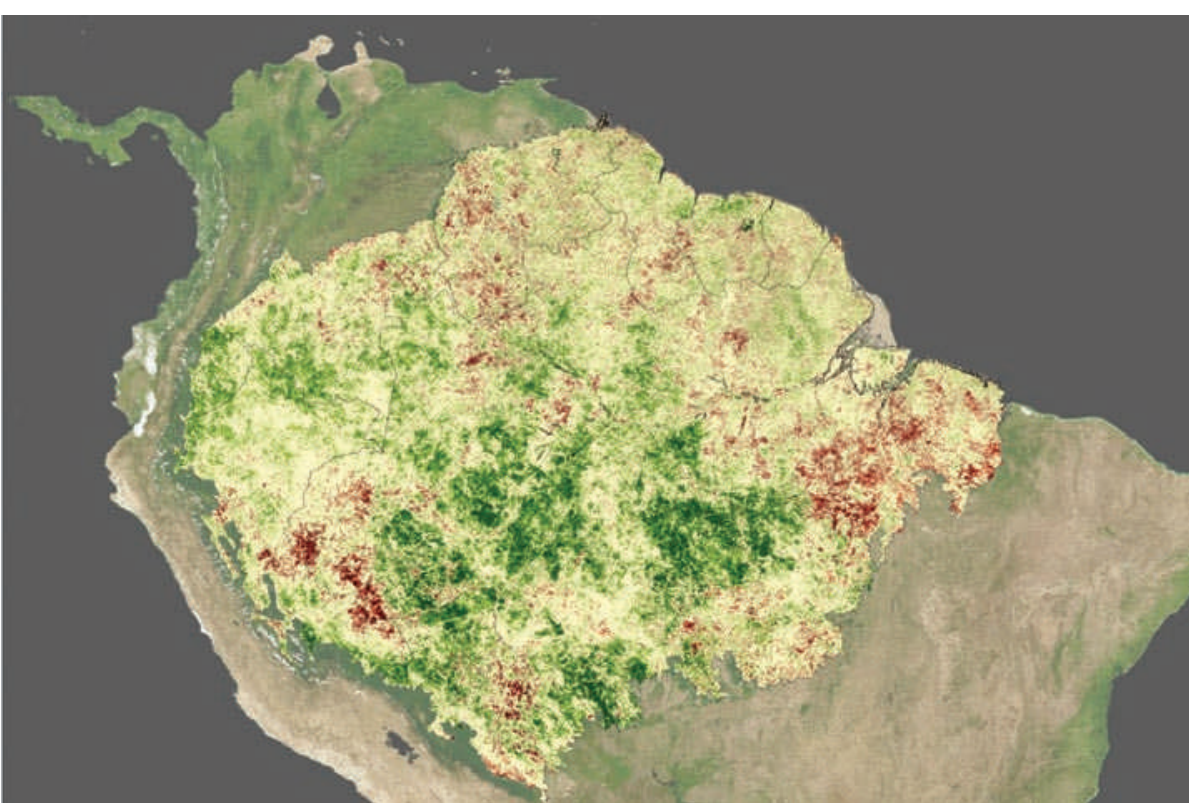

A controversial 2007 study found increased 'greening' in the Amazon rainforest during a drought in 2005.

than just drought, according to a separate report published online last month ${ }^{6}$.

Using a combination of satellite images and ground-based tree counts, the report estimated that an unusual cluster of powerful thunderstorms in January of that year knocked down more than half a billion trees. Those results do not necessarily undercut the drought research, which took place on plots unaffected by the storms. Nonetheless, it is a reminder that "there are many factors at play”, says Carlos Nobre, a scientist at Brazil's National Institute for Space Research in São José Dos Campos, who was not involved in the study. "Any time you try to explain basinwide phenomena with only one factor, you are probably going to be wrong," he says.

The uncertainties in understanding drought in the Amazon won't be reduced without better sensors in space, says Asner. In particular, he is pushing for NASA to prioritize a mission called the Hyperspectral Infrared Imager (HyspIRI), which would measure the subtle colour and chemical changes in the rainforest canopy in much more detail than the Terra satellite. Despite being high on the priority list of the Earth-science community, HyspIRI is not scheduled for launch until 2020. Asner laments, "We are going to be cruising for another decade with myopic goggles on."

Although drought has often been the focus of researchers gauging the impact of global warming on the Amazon, recent models suggest that the largest uncertainties stem from a different factor: how the forest responds to rising atmospheric carbon dioxide. By easing the burden of $\mathrm{CO}_{2}$ uptake, higher concentrations of the gas reduce water loss during photosynthesis. A strong $\mathrm{CO}_{2}$ fertilization effect not only boosts growth and carbon uptake, but could also offset reductions in precipitation thus increasing resilience to drought, says Peter Cox of the University of Exeter, UK, a co-author on four modelling studies in the New Phytologist issue.

But in the Northern Hemisphere, fertilization experiments - which involve pumping tonnes of $\mathrm{CO}_{2}$ into forest plots - indicate that the effect is limited by the availability of nutrients such as nitrogen. Tropical scientists want to know if the same is true in the Amazon. " $\mathrm{CO}_{2}$ fertilization is absolutely critical in the tropics, and we know absolutely nothing about it because we haven't done the experiments," says Cox. Jeff Tollefson

\footnotetext{
1. Saleska, S. R., Didan, K., Huete, A. R. \& da Rocha, H. R. Science 318, 612 (2007).

2. Samanta, A. et al. Geophys. Res. Lett. doi:10.1029/2009GL042154 (2009).

3. Asner, G. P. \& Alencar, A. New Phytol. 187, 569-578 (2010).

4. Phillips, O. L. et al. Science 323, 1344-1347 (2009).

5. da Costa, A. C. L. et al. New Phytol. 187, 579-591 (2010)

6. Negrón-Juárez. R. I. et al. Geophys. Res. Lett. doi:10.1029/2010GL043733 (in the press).
} 